\title{
KETERJANGKAUAN PETANI TERHADAP SUMBER INFORMASI \\ ( Studi Pada Anggota Kelompok Petani Pemakai Air (Kp2a) \\ Di Kecamatan Seginim Kabupaten Bengkulu Selatan )
}

\author{
Agus Purwoko ${ }^{1}$ \\ M. Zulkarnain Yuliarso ${ }^{1}$ \\ Weldyansyah $^{2}$ \\ ${ }^{1}$ Staf Pengajar Jurusan Sosial Ekonomi Pertanian Fak. Pertanian UNIB \\ ${ }^{2}$ Alumni Jurusan Sosial Ekonomi Pertanian Fak. Pertanian UNIB
}

\begin{abstract}
The object of this research was to identify about the exposure to sources information in water user farmer member group (KP2A), to know relation characteristic farmers group in $(K P 2 A)$ with sources of information and to know model and communication network in farmers member group of (KP2A) at Seginim District in South Bengkulu Regency. This research was conducted on 5 - 15 Desember 2006 at Seginim District. The research method use multistage random sampling for 60 members of farmers group. Result of this research indicated that five factors of the farmers such at formal education, income, experient in KP2A, motivation of work and perception to information related for the exposure to sourch of information there are on the middle category. The result of study indicated that ekxstention activity conducted with interactive models and all-channels comonity networking.
\end{abstract}

Keywords : members of water user farmers group (KP2A), exposure to sourch of information, model and comonity networks.

\section{PENDAHULUAN}

Peranan kelompok tani dalam sumber informasi adalah sebagai wadah informasi agar dapat menjangkau petani sebanyak-banyaknya dan juga merupakan wadah kegiatan dalam rangka memenuhi kebutuhan kelompok maupun anggotanya. Oleh karena itu, tujuan dari manfaat informasi adalah membantu petani agar senantiasa meningkatkan efesiensi usahanya melalui adopsi teknologi baru (Zulkarnain, 2004).

Untuk mencapai tujuan tersebut, dapat dilakukan dengan meningkatkan dinamika kelompok tani sehingga akan terjalin suatu interaksi sosial yang dinamis dalam kelompok masyarakat tersebut. Hal ini dapat terwujud melalui komunikasi yang kontinyu diantara anggota kelompok tani, dalam membentuk terciptanya jaringan komunikasi yang interaktif 
dan partisipatif agar tujuan utama kelompok tani seperti proses adopsi dan difusi inovasi dapat berjalan baik (Prabawa, 1988).

Informasi untuk masing-masing petani berbeda, tergantung keterjangkauan petani terhadap sumber informasi, baik yang berasal dari media antar pribadi, media kelompok, media publik ataupun media massa (Cangara, 2000). Tingkat keterjangkauan petani sebagai anggota KP2A terhadap berbagai sumber informasi akan menunjukan bagaimana tingkat kekosmopolitan dari media, dimana ciri-ciri kekosmopolitan ini adalah kemampuan untuk berinteraksi dengan anggota-anggota diluar sistem sosialnya serta kemampuan untuk memanfaatkan media sebagai sarana untuk mengembangkan potensi diri (Mardikanto, 1991).

Tersedianya berbagai media sumber informasi, belum menjamin kemudahan dalam mengakses informasi. Hal ini tidak hanya dipengaruhi oleh kemampuan berinteraksi, kepemilikan sarana media sebagai penyedia informasi, tetapi juga kemampuan memiliki dan menerima informasi dari media yang ada. Pemilihan dan pemanfaatan sumber informasi akan berbeda-beda untuk setiap kelompok tani tergantung pada karakteristik individu dan kebutuhan informasi.

Kebijakan pengelolaan sumber daya air yang menerapkan sistem irigasi yang partisipatif menempatkan Kelompok petani pemakai air (KP2A) sebagai pihak yang diharapkan dapat mengembangkan kelompok tani dalam mengelola irigasi sendiri karena mempunyai usaha pertanian yang berdimensi Agribisnis. Dengan demikian masing-masing anggota KP2A ini mempunyai tanggung jawab untuk dapat menambah pengetahuan melalui pengumpulan informasi mengenai inovasi dalam irigasi, baik dari penyuluh, media atau pun pihak lain.

Berdasarkan penjelasan diatas jelas bahwa informasi beserta sumbernya sangat penting untuk menambah pengetahuan pada petani mengenai ilmu usahatani. Bengkulu 
Selatan adalah salah satu Kabupaten penghasil beras di Propinsi Bengkulu yang rata-rata pengelolaan irigasinya telah melibatkan petani dalam wadah (kelompok petani pemakai air) KP2A khususnya di Kecamatan Seginim yang memliki perkembangan KP2A cukup baik. Penelitian ini akan mempelajari bagaimana sumber dan jenis informasi, keterjangkauan petani terhadap sumber informasi dan bagaimana jaringan serta model komunikasi pada KP2A di Kecamatan Seginim. Adapun maksud dari penelitian ini adalah untuk mengetahui Keterjangkauan anggota KP2A terhadap sumber informasi, Hubungan faktor-faktor dalam diri anggota KP2A terhadap sumber informasi, dan Model dan jaringan komunikasi anggota KP2A.

\section{METODE PENELITIAN}

Penelitian ini dilakukan di Kecamatan Seginim Kabupaten Bengkulu Selatan. Lokasi penelitian ditetapkan secara sengaja (Purposive) dengan pertimbangan daerah ini merupakan salah-satu pusat perkembangan KP2A di Kabupaten Bengkulu Selatan. Responden dalam penelitian ini adalah anggota KP2A di Kecamatan Seginim. Pengambilan sampel dilakukan dengan menggunakan teknik purposive sampling, dengan tahapan sebagai berikut: secara sengaja dipilih 6 desa yang memiliki KP2A dan dari masing-masing desa diambil 1 kelompok petani pemakai air, selanjutnya dari masing masing kelompok petani diambil 10 orang anggota petani yang dijadikan responden. Penentuan terhadap responden dilakukan dengan teknik Simple Random Sampling Dengan demikian jumlah responden yang diambil sebanyak 60 orang anggota KP2A.

Tingkat keterjangkauan petani KP2A pada sumber informasi dihubungkan dengan faktor - faktor dari dalam diri anggota KP2A. Untuk menggambarkan hubungan variabel yang ingin diketahui diberikan tiga alternatif jawaban. Jawaban yang diberikan berdasarkan tingkatannya, dimana variabel yang akan diteliti yaitu pendidikan, Pendapatan usahatani, pengalaman, motivasi menjadi anggota KP2A katagorinya (tinggi, sedang, 
rendah), persepsi katagorinya (baik, sedang, jelek) dihubungkan dengan keterjangkauan terhadap sumber informasi media interpersonal (penyuluh) dan media massa (TV, radio, koran dan majalah).

Untuk mengetahui apakah ada hubungan antar variabel yang diamati dengan keterjangkauan anggota pada sumber informasi dilakukan dengan menggunakan analisa statistik non parametrik, yaitu uji Koefisien Rank Spearman (rs) dengan rumus (Siegel, 1992) :

$$
r s=1-\frac{6 \sum_{i-1}^{N} d i^{2}}{N^{3}-N}
$$

Dimana :

$$
\begin{array}{ll}
\text { rs } & =\text { Koefisien Korelasi Rank Spearman } \\
N & =\text { Jumlah Responden } \\
\text { di } & =\text { Selisih antara rangking variabel bebas dengan variabel tak bebas } \\
\mathrm{i} & =\text { Nomor responden }(1,2,3, \ldots \mathrm{n}) \\
6 & =\text { Konstanta }
\end{array}
$$

jika terdapat adanya nilai observasi yang sama (ties) maka digunakan selisih antara suatu variabel bebas dengan rangking variabel terikat pada responden ada nilai sama Faktor koreksinya yaitu :

$$
T=\frac{t^{3}-t}{12}
$$

Sehingga rumus Rank Spearman menjadi :

$$
\begin{aligned}
& r_{s}=\frac{\sum X^{2}+\sum Y^{2}+\sum d i^{2}}{2 \sqrt{\sum X^{2} \sum Y^{2}}} \\
& \sum X^{2}=\frac{N^{3}-N}{12}-\sum T_{x} \\
& \sum Y^{2}=\frac{N^{3}-N}{12}-\sum T_{y}
\end{aligned}
$$

Dimana : 


$$
\begin{aligned}
& \sum X=\text { Jumlah kuadrat variabel bebas yang dikoreksi } \\
& \sum Y=\text { Jumlah kuadrat variabel tak bebas yang dikoreksi } \\
& \sum T_{x}=\text { Jumlah faktor koreksi variabel bebas } \\
& \sum T_{y}=\text { Jumlah faktor koreksi variabel tak bebas }
\end{aligned}
$$

Untuk menguji signifikansi hubungan tersebut di atas, maka t hitung (observasi) dibandingkan dengan $\mathrm{t}$ table dengan dua arah sisi dengan tingkat signifikansi yang digunakan adalah $95 \%(\dot{\alpha}=0,05)$, t hitung dapat dicari dengan rumus sebagai berikut :

$$
t_{\text {hitung }}=r s \sqrt{\frac{N-2}{1-(r s)^{2}}}
$$

Dimana :

$r s=$ Koefisien korelasi rank spearman

$\mathrm{N}=$ Jumlah responden

Hipotesisnya secara matematisnya adalah sebagai berikut :

Ho : rs $=0$ : Variabel bebas berhubungan nyata dengan variabel terikat

Hi : rs $\neq 0$ : Variabel bebas tidak berhubungan nyata dengan variabel terikat

Dengan kaidah pengujian sebagai berikut :

- Jika $\mathrm{t}$ hit $\geq \mathrm{t}$ tabel atau - $\mathrm{t}$ hit $\leq-\mathrm{t}$ tabel, maka Ho ditolak, artinya : berhubungan nyata variabel bebas dengan variabel tak bebas.

- Jika - $\mathrm{t}$ tabel $<\mathrm{t}$ hit $<\mathrm{t}$ tabel, maka Ho diterima, artinya : variabel bebas berhubungan tidak nyata dengan variabel tak bebas.

Mengenai cara atau model komunikasi yang digunakan oleh anggota dianalisa dengan menggunakan analisis deskriptif yaitu dengan memaparkan data atau informasi yang telah didapatkan mengenai cara anggota KP2A berkomunikasi dalam kelompok baik untuk menyampaikan maupun mendapatkan informasi melalui wawancara dan sumber lainya mengenai jaringan dan model komunikasi yang digunakan oleh anggota KP2A. 


\section{Tingkat Keterjangkauan Anggota KP2A Pada Sumber Informasi}

Keterjangkauan pada sumber informasi adalah kemampuan dalam menterdedahkan diri dalam mengakses atau mencari informasi tentang pengelolaan KP2A yang pencarian sumber informasinya mencakup pada media interpersonal (penyuluhan) dan media massa (TV, Radio, Koran dan Majalah).

\section{Tingkat Keterjangkauan Pada Media Interpersonal (Penyuluhan)}

Perubahan pada diri manusia yang diharapkan dapat terjadi karena adanya kegiatan penyuluhan adalah pengetahuan, keterampilan dan sikapnya. Dalam pelaksanaan kegiatan penyuluhan pertanian sasaran yang dingin dicapai juga berupa peningkatan pengetahuan keterampilan dan sikap petani sehingga mereka akan mampu untuk mandiri, dapat dilihat pada Table 10 di bawah ini.

Pada Tabel 9 dapat diketahui bahwa sebanyak 83,4\% anggota memiliki motivasi kerja dengan kategori tinggi, kemudian 8,3\% anggota dengan kategori sedang hanya 8,3\% anggota dengan kategori rendah. Rata-rata skor motivasi kerja anggota KP2A adalah 36,3. kondisi motivasi kerja tinggi tinggi disebabkan adanya keinginan untuk memperoleh pendapatan yang lebih baik dari usahatani padi. Salah satunya haruslah didukung oleh pengairan yang baik yaitu dengan irigasi yang pengelolaannya melalui organisasi KP2A.

Tabel 10. Keterjangkauan pada media interpersonal (penyuluhan)

\begin{tabular}{lccc}
\hline \multicolumn{1}{c}{ Kategori interpersonal } & Persentase & Rata-rata skor & Kisaran skor \\
\hline Tinggi $(>105)$ & 31,7 & & \\
Sedang $(75 \leq \mathrm{x} \leq 105)$ & 55 & 18,96 & 9 s/d 27 \\
Rendah $(<75)$ & 13,3 & & \\
\hline
\end{tabular}

Sumber: Data primer diolah, Februari 2007

Pada Tabel 10 dapat dijelaskan bahwa tingkat keterjangkauan anggota KP2A banyak terdapat pada katagori sedang yaitu 55\% sedangkan sisanya pada kagori tinggi sebanyak $31,7 \%$ dan rendah sebanyak $13,3 \%$. Kondisi tersebut bisa dikatakan bahwa untuk keterjangkauan pada media interpersonal cukup tinggi, disebabkan karena kegiatan 
penyuluhan yang di selenggarakan di daerah penelitian tidak hanya dilakukan oleh PPL saja tetapi ada peran serta pemerintah dan aparat terkait seperti kimpraswil daerah Kabupaten setempat yang memberikan informasi dan pengarahan tentang bagaimana pemanfaatan air dan pengelolaan irigasi yang baik.

\section{Tingkat Keterjangkauan Pada Media Massa (TV, Radio, Koran dan Majalah)}

Pembangunan pedesaan pelaksanaannya memerlukan berbagai macam sumberdaya termasuk media massa. Media massa mudah menyebabkan masyarakat menjadi kosmopolit Untuk mengetahui tingkat keterjangkauan anggota KP2A pada media massa dapat dilihat pada Tabel 11 di bawah ini.

Tabel 11 Keterjangkauan pada media massa

\begin{tabular}{lccc}
\hline \multicolumn{1}{c}{ Kategori media massa } & Persentase & Rata-rata skor & Kisaran skor \\
\hline Tinggi $(>105)$ & 16,7 & & \\
Sedang $(75 \leq \mathrm{x} \leq 105)$ & 56,6 & 67,1 & 36 s/d 108 \\
Rendah $(<75)$ & 26,7 & & \\
\hline
\end{tabular}

Sumber: Data primer diolah, Februari 2007

Pemanfaatan media massa seperti $\mathrm{TV}$, radio, Koran dan majalah pertanian mayoritas terdapat pada katagori sedang 56,6\% hal ini dikarenakan masih kurangnya kesadaran anggota KP2A untuk lebih aktif lagi menterdedahkan diri pada media massa dan hal ini juga dipengaruhi oleh terbatasnya informasi mengenai KP2A dari media massa. Surat kabar yang tersedia, di lokasi penelitian masih merupakan harian umum. Informasi yan diperoleh dari radio biasanya yang berkaitan tentang kondisi harga beras dan komoditi pertanian lainnya, sedangkan media TV lebih banyak menjadi media hiburan saja karena jarang ada informasi yang secara khusus tentang pertanian dan irigasi.

\section{Tingkat Keterjangkauan Pada Sumber informasi}

Dua macam media informasi yang memiliki potensi besar untuk mendukung pembangunan pedesaan ialah media massa dan media interpersonal / penyuluhan, Kedua media informasi ini memiliki kemampuan yang besar untuk mengantarkan dan 
menyebarkan pesan-pesan pembangunan kepada petani yang berada di tempat terpencar dan tersebar luas. Untuk lebih jelasnya dapat dilihat pada Tabel 8 di bawah ini.

Tabel 12 Keterjangkauan pada media interpersonal dan media massa

\begin{tabular}{lccc}
\hline $\begin{array}{c}\text { Kategori interpersonal dan media } \\
\text { massa }\end{array}$ & Persentase & Rata-rata skor & Kisaran skor \\
\hline Tinggi $(>105)$ & 11,7 & & \\
Sedang $(75 \leq \mathrm{x} \leq 105)$ & 63,3 & 76,31 & $45 \mathrm{~s} / \mathrm{d} 135$ \\
Rendah $(<75)$ & 25 & & \\
\hline
\end{tabular}

Sumber: Data primer diolah, Februari 2007

Berdasarkan data tabel diatas tingkat keterjangkauan anggota KP2A kepada sumber informasi yang dilihat secara keseluruhan terdapat pada katagori sedang yaitu sebesar 63,3\%, hal ini bisa jadi disebabkan oleh masih kurangnya kemampuan dan kesadaran masyarakat untuk menterdedahkan diri pada kedua media informasi ini. Dan juga dipengaruhi oleh tingkat kesejahteraan masyarakat yang rata-rata pada kondisi pas-pasan sehingga mereka lebih memperioritaskan pada kebutuhan pangan.

\section{Analisis Hubungan Karakteristik Anggota KP2A Dengan Tingkat Keterjangkauan Pada Media Interpersonal dan Media Massa}

Untuk melihat hubungan antara pendidikan formal, pendapatan, pengalaman dalam keanggotaan di KP2A, Pendapatan Usahatani, persepsi terhadap informasi dan motivasi kerja dengan tingkat keterjangkauan pada sumber informasi digunakan uji Rank Spearman.

Hasil uji statistik yang dilakukan dapat dilihat pada tabel 9

Tabel 12 Hasil Analisis Korelasi Rank Spearman Variabel Xi dan Variabel Y

\begin{tabular}{cclccc}
\hline No & & Variabel bebas & $\mathrm{Y}_{1}$ & $\mathrm{Y}_{2}$ & $\mathrm{Y}_{3}$ \\
\hline 1 & $\mathrm{x} 1$ & Pendidikan formal & $0.00940(0.07160)$ & $0.00165(0.01259)$ & $0.01679(0.12796)$ \\
\hline 2 & $\mathrm{x} 2$ & Pendapatan petani & $\begin{array}{c}-0.33164^{*}(- \\
2.67721)\end{array}$ & $0.07764(0.59315)$ & $\begin{array}{c}-0.00262(- \\
0.02002)\end{array}$ \\
\hline 3 & $\mathrm{x} 3$ & Pengalaman di KP2A & $0.34477^{*}(2.79721)$ & $0.10771(0.82513)$ & $0.18774(1.45571)$ \\
\hline \multirow{2}{*}{4} & $\mathrm{x} 4$ & $\begin{array}{l}\text { Persepsi tentang } \\
\text { informasi }\end{array}$ & $0.44823^{*}(3.81874)$ & $\begin{array}{c}0.90145^{*} \\
(15.8595)\end{array}$ & $\begin{array}{c}0.93275^{*} \\
(19.7043)\end{array}$ \\
\hline 5 & $\mathrm{x} 5$ & Motivasi kerja & $0.29840^{*}(2.38106)$ & $0.52921^{*}$ & $0.56821^{*}$ \\
\hline
\end{tabular}


Sumber: Data primer diolah, Februari 2007

\section{Keterangan :}

$\mathrm{Y}_{1} \quad:$ media interpersonal

$\mathrm{Y}_{2} \quad$ : media massa

$\mathrm{Y}_{3} \quad:$ media interpersonal dan media massa (gabungan)

$\mathrm{t}(58: 0,05) \quad:(2,002)$

: $\quad$ Angka-angka dalam kurung adalah nilai t hitung Xi terhadap Yi. Tabel 12 Hasil

Analisis Korelasi Rank Spearman Variabel Xi dan Variabel Y

\begin{tabular}{cclccc}
\hline No & & Variabel bebas & $\mathrm{Y}_{1}$ & $\mathrm{Y}_{2}$ & $\mathrm{Y}_{3}$ \\
\hline 1 & $\mathrm{x} 1$ & Pendidikan formal & $0.00940(0.07160)$ & $0.00165(0.01259)$ & $0.01679(0.12796)$ \\
\hline 2 & $\mathrm{x} 2$ & Pendapatan petani & $\begin{array}{c}-0.33164^{*}(- \\
2.67721)\end{array}$ & $0.07764(0.59315)$ & $\begin{array}{c}-0.00262(- \\
0.02002)\end{array}$ \\
\hline 3 & $\mathrm{x} 3$ & Pengalaman di KP2A & $0.34477^{*}(2.79721)$ & $0.10771(0.82513)$ & $0.18774(1.45571)$ \\
\hline \multirow{2}{*}{4} & \multirow{2}{*}{ x4 } & $\begin{array}{l}\text { Persepsi tentang } \\
\text { informasi }\end{array}$ & $0.44823^{*}(3.81874)$ & $\begin{array}{l}0.90145^{*} \\
(15.8595)\end{array}$ & $\begin{array}{c}0.93275^{*} \\
(19.7043)\end{array}$ \\
\hline \multirow{2}{*}{5} & \multirow{2}{*}{ x5 } & Motivasi kerja & $0.29840^{*}(2.38106)$ & $\begin{array}{l}0.52921^{*} \\
(4.56821)\end{array}$ & $\begin{array}{c}0.56821^{*} \\
(5.25880)\end{array}$ \\
\hline
\end{tabular}

Sumber: Data primer diolah, Februari 2007

\section{Keterangan :}

$\mathrm{Y}_{1} \quad:$ media interpersonal

$\mathrm{Y}_{2} \quad$ : media massa

$\mathrm{Y}_{3} \quad:$ media interpersonal dan media massa (gabungan)

$\mathrm{t}(58: 0,05) \quad:(2,002)$

: Angka-angka dalam kurung adalah nilai t hitung Xi terhadap Yi.

\section{a. Pendidikan Formal}

Hasil analisis menunjukkan bahwa variabel pendidikan tidak berhubungan nyata dengan tingkat keterjangkauan anggota KP2A pada sumber informasi dengan taraf kepercayaan 95\%. Hal ini dapat dilihat pada t-hitung yang lebih kecil dari t-tabel untuk $\mathrm{Y}_{1}$ $(0.07160<2,002), \mathrm{Y}_{2}(0.01259<2,002)$, dan $\mathrm{Y}_{3}(0.12796<2,002)$. Kondisi ini disebabkan karena untuk mendapatkan informasi mengenai pengelolaan irigasi, anggota KP2A tidak harus memiliki tingkat pendidikan formal yang tinggi. Anggota KP2A 
memiliki keterampilan dan pengetahuan yang berbeda satu sama lain, di mana anggota KP2A berpendidikan tinggi belum tentu memiliki keterampilan dan pengetahuan yang lebih tinggi dalam mencari informasi dibandingkan dengan anggota KP2A yang berpendidikan rendah. Hal ini dapat dilihat dari kenyataan di lapangan dimana anggota KP2A melakukan kegiatan usahataninya secara turun-menurun atau tradisional. Mereka hanya melakukannya berdasarkan pengetahuan yang dimiliki dari anggota KP2A sekitar serta pengelolaannya dari tahun ke tahun tidak mengalami banyak perubahan yang berarti.

\section{b. Pendapatan}

Hasil analisis menunjukan bahwa variabel pandapatan petani untuk $\mathrm{Y}_{2}$ dan $\mathrm{Y}_{3}$ tidak berhubungan nyata dengan tingkat keterjangkauan anggota KP2A pada sumber informasi pada taraf kepercayaan 95\% dimana t-hitung lebih besar dari t-tabel pada $\mathrm{Y}_{2}(0.59315>$ 2,002) dan $\mathrm{Y}_{3}(-0.02002>-2,002)$ sehingga tolak Ho dan terima Hi. Sementara itu, hasil analisis pada $Y_{1}$ menunjukan bahwa variabel pendapatan berhubungan nyata terhadap tingkat keterjangkauan anggota KP2A pada sumber informasi interpersonal dengan taraf kepercayaan 95\% dimana nilai t-hitung sebesar (-2.67721) lebih besar dari t-tabel sebesar $(-2,002)$ artinya Ho ditolak dan Hi diterima. Hasil ini menunjukan bahwa sehingga tingkat pendapatan hanya berhubungan untuk tingkat keterjangkauan anggota KP2A pada media interpersonal (penyuluhan).

Tidak adanya hubungan yang nyata antara pendapatan dengan tingkat keterjangkauan pada $Y_{2}$ (media massa) dan $Y_{3}$ media interpersonal dan media massa (gabungan) karena adanya sikap dari anggota KP2A yang enggan untuk mengeluarkan biaya untuk meningkatkan pengetahuan atau untuk mendapatkan informasi yang baru mengenai pengelolaan KP2A. Hal ini dikarenakan rata-rata pendapatan anggota KP2A yang masih dalam katagori sedang. Untuk mendapatkan informasi pada media massa anggota KP2A harus mengeluarkan biaya. Untuk variable $\mathrm{Y}_{1}$ tingkat pendapatan berpengaruh nyata. 
Adanya hubungan nyata yang negatif antara pendapatan dengan tingkat keterjangkauan anggota KP2A pada media interpersonal karena mereka cendrung bertanya secara langsung pada penyuluh dan sesama petani untuk mendapatkan informasi. Pendapatan anggota KP2A yang terbilang tinggi mereka lebih cendrung dibelanjakan untuk keperluan makan, pakaian dan keperluan lainnya dari pada mengeluarkan biaya untuk membeli Koran petanian, majalah pertanian dsb. Hal ini mungkin dipengaruhi oleh keadaan lingkungan sekitar yang masih terbilang terkukung dalam komunitas yang tradisional dalam mengakses informasi.

\section{c. Pengalaman Menjadi Anggota KP2A}

Hasil analisis menunjukan bahwa variabel pengalaman untuk $\mathrm{Y}_{2}$ dan $\mathrm{Y}_{3}$ tidak berhubungan nyata dengan tingkat keterjangkauan pada sumber informasi pada taraf kepercayaan 95\% dengan nilai t-hitung lebih kecil dari t-tabel $(0.82513<2,002)$ untuk $\mathrm{Y}_{2}$ dan $(1.45571<2,002)$ untuk $\mathrm{Y}_{3}$. Tidak adanya hubungan nyata antara pengalaman di KP2A dengan keterjangkauan pada sumber informasi karena kegiatan usahatani dilakukan secara turun - temurun sehingga petani sudah mempunyai konsep dan cara sendiri untuk mengelola irigasi sedangkan informasi baru yang didapatkan belum tentu dimengerti dan sesuai untuk diterapkan di lokasi pertanian mereka. Hasil analisis pada $\mathrm{Y}_{2}$ dan $\mathrm{Y}_{3}$ bertolak belakang dengan hasil analisis pada $\mathrm{Y}_{1}$ dimana tingkat pengalaman di KP2A berhubungan nyata dengan tingkat keterjangkauan pada sumber informasi pada taraf kepercayaan $95 \%$ dengan nilai t-hitung lebih besar dari nilai t-tabel $(2.79721$ >2,002). Artinya semakin berpengalaman anggota KP2 cenderung lebih mempercayai atau semakin sering untuk menterdedahkan diri pada penyuluh dan sesama anggota KP2A. Anggota KP2A yang lebih berpengalaman cenderung untuk lebih membuka diri pada penyuluhan untuk mendapatkan masukan-masukan baru yang tentu saja bermanfaat untuk kelancaran irigasi dan usaha pertaniannya. 


\section{d. Persepsi Terhadap Informasi KP2A}

Persepsi anggota KP2A terhadap informasi berhubungan nyata terhadap tingkat keterjangkauan anggota KP2A pada sumber informasi baik dari media interpersonal, media massa maupun media gabungan (media interpersonal dan media massa) pada taraf kepercayaan 95\% dengan koefisien korelasi untuk $\mathrm{Y}_{1}$ sebesar $0.44823, \mathrm{Y}_{2} 0.90145$ dan $\mathrm{Y}_{3}$ 0.93275. Nilai t-hitung juga lebih besar dari t-tabel pada $\mathrm{Y}_{1}$ sebesar $(3.81874>2,002), \mathrm{Y}_{2}$ $(15.8595>2,002)$, dan $\mathrm{Y}_{3}(19.7043>2,002)$ yang berarti Ho ditolak dan Hi diterima. Anggota KP2A memiliki pandangan yang baik terhadap sumber informasi baik media interpersonal dan media massa. Mereka yakin apabila informasi mempunyai manfaat yang mereka butuhkan dan membantu kemudahan mereka dalam mengelola serta memanfaatkan irigasi, mereka berusaha akan selalu mencarinya kemudian memanfaatkanya

\section{e. Motivasi Kerja Anggota KP2A}

Hasil analisis menunjukan bahwa variabel motivasi kerja anggota KP2A berhubungan nyata dengan tingkat keterjangkauan pada sumber informasi baik untuk $\mathrm{Y}_{1}$, $\mathrm{Y}_{2}$, dan $\mathrm{Y}_{3}$ pada taraf kepercayaan 95\%. Hal ini dapat dilihat pada t-hitung yang lebih besar dengan t-tabel untuk $\mathrm{Y}_{1}(2.38106>2,002) \mathrm{Y}_{2}(4.56821>2,002)$ dan $\mathrm{Y}_{3}(5.25880>$ 2,002) Dengan demikian Ho ditolak dan Hi diterima. Hal ini berarti bahwa semakin besar motivasi kerja anggota KP2A akan mengakibatkan tingkat keterjangkauan mereka pada sumber informasi akan semakin tinggi pula. Berdasarkan pengamatan yang dilakukan di lokasi penelitian, untuk meningkatkan pengetahuan dan keterampilan di dalam berusahatani, petani berusaha bekerja lebih baik dibandingkan anggota lain. Motivasi tinggi yang dimiliki oleh anggota KP2A akan sangat membantu dalam menterdedahkan diri pada sumber informasi

\section{Model dan Jaringan Komunikasi Anggota KP2A}


Komunikasi adalah suatu pernyataan antar manusia, baik secara perorangan maupun kelompok, yang bersifat umum (tidak bersifat rahasia) dengan menggunakan tanda-tanda, kode-kode atau lambang-lambang tertentu. Pada prinsipnya setiap anggota KP2A selalu melakukan interaksi sosial dengan anggota KP2A yang lain, maka komunikasi dalam bentuk kelompok tidak dapat dihindarkan oleh setiap anggota KP2A. Bagi anggota KP2A, komunikasi kelompok ini sangat bermanfaat karena dengan adanya interaksi antar individu baik di luar dan di dalam kelompok yang memberikan manfaat bagi bersama yaitu komunikasi yang baik dan terjaga antar anggota KP2A.

Komunikasi dilakukan oleh anggota KP2A dalam rapat rutin kelompok KP2A, waktu menghadiri penyuluhan dan pertemuan yang bersifat kelompok lainnya (undangan dari aparat pemerintah). Peranan KP2A dalam penyebaran informasi pertanian mengenai irigasi adalah sebagai wadah informasi agar dapat menjangkau anggota KP2A yang lain dan juga sebagai wadah kegiatan dalam rangka memenuhi kebutuhan kelompok maupun anggotanya. Oleh karena itu tujuan akhir dari komunikasi pertanian yang dilakukan oleh anggota KP2A dalam kelompok ini adalah untuk membantu anggota yang lain agar senantiasa memperbaiki kualitas pengelolaan irigasi melalui adopsi teknologi baru yang didapat penyebaran informasi baru antar sesama anggota dalam kelompok.

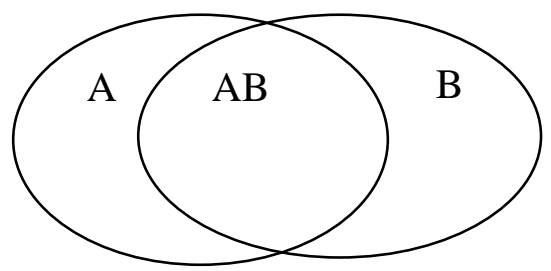

\section{Gambar 2.}

Pada diagram di atas tidak terdapat pengirim maupun penerima. Baik A ataupun B merupakan partisipan dalam proses komunikasi yang dilakukan anggota KP2A dalam melakukan komunikasi. A akan mengirim pesan kepada B, dan B secara aktif akan 
berpartisipasi dalam proses tersebut dengan jalan menjadi aktif dan selektif pada pesanpesan yang akan dikirim oleh A. Dalam kenyataan dilapangan terdapat lebih dari 2 partisipan dalam suatu proses komunikasi atau sebaliknya, sehingga pada suatu saat akan ada sejumlah lingkaran-lingkaran atau ruang yang saling tupang tindih.

\section{a. Jaringan Komunikasi Anggota KP2A}

Jaringan komunikasi dalam Kelompok Tani Pemakai Air merujuk pada jaringan komuniasi semua saluran All-Channels (Tubbs and Moss, 1996 dalam Jahi, 1988) seperti gambar dibawah ini

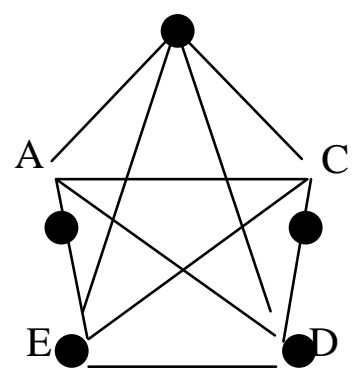

\section{Gambar 3.}

Jaringan komunikasi semua saluran termasuk termasuk dalam jaringan yang tidak terpusat, Artinya semua saluran komunikasi bersifat terbuka, sehingga setiap orang dapat berkomunikasi dengan semua anggota lainnya tanpa adanya pembatas. Menurut Shaw (1964) dalam Tubbs dan Mass, (1996), komunikasi dalam jaringan ini sangat baik apabila menghadapi masalah yang rumit dan memerlukan proses diskusi dalam penyelesaian masalah tersebut. Jaringan komunikasi saluran ini mereka rasakan lebih memberikan kepuasan kepada anggota kelompok karena mampu memberikan kesempatan kepada setiap anggota kelompok untuk berbicara sehingga dapat melakukan umpan balik dan koreksi yang akhirnya menghasilkan kesepahaman bersama yang lebih memberikan kepuasan masing-masing.

\section{KESIMPULAN DAN SARAN}




\section{Kesimpulan}

Beberapa kesimpulan yang dapat ditarik dari hasil penelitian ini adalah :

1) Keterjangkauan anggota KP2A terhadap sumber informasi tergolong baik, rata-rata anggota KP2A memanfaatkan media interpersonal (penyuluhan) dan media massa (TV, radio, Koran dan majalah) untuk mendapatkan sumber informasi. Sumber informasi yang dominan menjadi panutan dalam pengambilan keputusan setiap kegiatan dalam organisasi KP2A adalah media interpersonal yaitu penyuluhan, serta TV dan radio.

2) Karakteristik anggota KP2A yang berhubungan nyata dengan variable $Y_{1}$ (media interpersonal) adalah pendapatan, pengalaman, persepsi dan motivasi. Untuk variable $\mathrm{Y}_{2}$ (media massa) adalah persepsi dan motivasi. Dan untuk variable $\mathrm{Y}_{3}$ (keterjangkauan terhadap sumber informasi) adalah persepsi dan motivasi.

3) Model komunikasi yang terlihat dalam kegiatan penyuluhan di daerah penelitian mengacu pada model komunikasi interaktif dan konvergen. Jaringan komunikasi dalam kelompok petani pemakai air (KP2A) di lokasi penelitian adalah jaringan semua saluran (All-Channel).

\section{Saran}

Kebutuhan informasi petani perlu diimbangi dengan ketersediaan sumber-sumber informasi yang lebih lengkap dan terarah. Sehingga perlu dipertimbangakan beberapa hal sebagai berikut :

1. Sumber informasi interpersonal merupakan media yang strategis untuk menyampaikan informasi pertanian. Penambahan jumlah agen pembaharu seperti penyuluh sangat diperlukan untuk memberi informasi sesuai kebutuhan petani terutama di desa-desa yang kurang akses terhadap sumber informasi. 
2. Informasi yang diberikan melalui siaran radio dan televise hendaknya lebih memperhatikan kesesuaian dengan kebutuhan khalayak sasaran.

3. Media massa yang menjangkau khalayak petani, disertai dengan panduan penyulu maka akan dapat memantapkan informasi yang diterima melalui media cetak dan elektronik.

\section{DAFTAR PUSTAKA}

Cangara, H. 2000. Pengantar Komunikasi. Liberty, Jakarta.

Jahi, A. 1988. Komunikasi Massa dan Pembangunan Pedesaan Di Negara-Negara Dunia Ketiga. Gramedia, Jakarta.

Mardikanto, T. 1991. Penyuluhan Pembangunan Pertanian. UNS. Press, Surakarta.

Prabawa, F.E. 1988. Dinamika Kelompok Tani dalam Proses Adopsi dan Difusi Inovasi. Institut Pertanian Bogor, Bogor.

Siegel, S. 1992. Statistik Non Parametrik untuk Ilmu- ilmu Sosial. Cet. Ke-5. Gramedia, Jakarta.

Tubbs,S. dan S, Mass. 1996. Human Comunication “Human Comunication” Terjemahan oleh Redy Mulyana dan Gembira Sari. Remaja Radakarya, Bandung.

Zulkarnain, M.Y. 2004. Analisis Jaringan Komunikasi Pada Kelompok Tani Mitra Tani, Desa Petir Kecamatan Dramaga Bogor, Penelitian Institut Pertanian Bogor, Bogor.(Tidak Dipublikasikan). 